\title{
Biological and Tribological Assessment of Poly(Ethylene Oxide Terephthalate)/Poly(Butylene Terephthalate), Polycaprolactone, and Poly (LIDL) Lactic Acid Plotted Scaffolds for Skeletal Tissue Regeneration
}

Citation for published version (APA):

Hendrikson, W. J., Zeng, X., Rouwkema, J., van Blitterswijk, C. A., van der Heide, E., \& Moroni, L. (2016). Biological and Tribological Assessment of Poly(Ethylene Oxide Terephthalate)/Poly(Butylene Terephthalate), Polycaprolactone, and Poly (LIDL) Lactic Acid Plotted Scaffolds for Skeletal Tissue Regeneration. Advanced Healthcare Materials, 5(2), 232-243. https://doi.org/10.1002/adhm.201500067

Document status and date:

Published: 21/01/2016

DOI:

10.1002/adhm.201500067

Document Version:

Publisher's PDF, also known as Version of record

\section{Document license:}

Taverne

Please check the document version of this publication:

- A submitted manuscript is the version of the article upon submission and before peer-review. There can be important differences between the submitted version and the official published version of record. People interested in the research are advised to contact the author for the final version of the publication, or visit the $\mathrm{DOI}$ to the publisher's website.

- The final author version and the galley proof are versions of the publication after peer review.

- The final published version features the final layout of the paper including the volume, issue and page numbers.

Link to publication

\footnotetext{
General rights rights.

- You may freely distribute the URL identifying the publication in the public portal. please follow below link for the End User Agreement:

www.umlib.nl/taverne-license

Take down policy

If you believe that this document breaches copyright please contact us at:

repository@maastrichtuniversity.nl

providing details and we will investigate your claim.
}

Copyright and moral rights for the publications made accessible in the public portal are retained by the authors and/or other copyright owners and it is a condition of accessing publications that users recognise and abide by the legal requirements associated with these

- Users may download and print one copy of any publication from the public portal for the purpose of private study or research.

- You may not further distribute the material or use it for any profit-making activity or commercial gain

If the publication is distributed under the terms of Article $25 \mathrm{fa}$ of the Dutch Copyright Act, indicated by the "Taverne" license above,

Download date: 26 Apr. 2023 


\title{
Biological and Tribological Assessment of Poly(Ethylene Oxide Terephthalate)/Poly(Butylene Terephthalate), Polycaprolactone, and Poly (LDL) Lactic Acid Plotted Scaffolds for Skeletal Tissue Regeneration
}

\author{
Wilhelmus J. Hendrikson, Xiangqiong Zeng,"* Jeroen Rouwkema, Clemens A. van Blitterswijk, \\ Emile van der Heide, and Lorenzo Moroni
}

Additive manufactured scaffolds are fabricated from three commonly used biomaterials, polycaprolactone (PCL), poly (L/DL) lactic acid (P(L)DL)LA), and poly(ethylene oxide terephthalate)/poly(butylene terephthalate) (PEOT/PBT). Scaffolds are compared biologically and tribologically. Cell-seeded PEOT/PBT scaffolds cultured in osteogenic and chondrogenic differentiation media show statistical significantly higher alkaline phosphatase (ALP) activity/DNA and glycosaminoglycans (GAG)/DNA ratios, followed by PCL and P(L/DL)LA scaffolds, respectively. The tribological performance is assessed by determining the friction coefficients of the scaffolds at different loads and sliding velocities. With increasing load or decreasing sliding velocity, the friction coefficient value decreases. PEOT/PBT show to have the lowest friction coefficient value, followed by $P C L$ and $P(L \mid D L) L A$. The influence of the scaffold architecture is further determined with PEOT/PBT. Reducing of the fiber spacing results in a lower friction coefficient value. The best and the worst performing scaffold architecture are chosen to investigate the effect of cell culture on the friction coefficient. Matrix deposition is low in the cell-seeded scaffolds and the effect is, therefore, undetermined. Taken together, our studies show that PEOT/PBT scaffolds support better skeletal differentiation of seeded stromal cells and lower friction coefficient compared to PCL and P(L/DL)A scaffolds.

\section{Introduction}

Normal joint function relies on low joint friction in combination with the adsorption and transmission of loads by healthy articular cartilage. Treatments of articular defects are challenging as the regenerating capacity of cartilage is low. For treating these defects, it is of the utmost importance to obtain a friction coefficient as low as possible for smooth articulation. Matrixassisted autologous chondrocyte implantation, microfracture, and mosaic plasty are some of the treatments to regenerate or repair the malfunctioning tissue. Despite a certain degree of success, these treatments suffer from a number of drawbacks where donor site morbidity, graft availability, and immunological rejection are the most recurring problems. ${ }^{[1,2]}$ This results in a frequent degeneration of the regenerated or repaired articular tissue, and consequently in an increase of friction, a decrease of mobility, and a new surgery to be planned. Therefore, the goal of tissue engineering is to provide grafts with appropriate biological and mechanical properties that can regenerate functional articular tissues. For restoring or regenerating a malfunctioning tissue, a temporary scaffold is often needed which has the ability of inducing signals for cells to form the desired tissue. The biomaterial itself, ${ }^{[3]}$ surface topography ${ }^{[4]}$ and the biomaterial's bulk stiffness ${ }^{[5]}$ are a few properties of a scaffold, capable of influencing cell differentiation. These properties are to a certain extent tailorable and can be employed to evoke specific cell differentiation signals. ${ }^{[6-8]}$

\author{
W. J. Hendrikson, Prof. C. A. van Blitterswijk, Dr. L. Moroni \\ Department of Tissue Regeneration \\ MIRA Institute for Biomedical Technology and Technical Medicine \\ University of Twente \\ Enschede 7500, AE, The Netherlands \\ Dr. X. Zeng, Prof. E. van der Heide \\ Laboratory for Surface Technology and Tribology \\ Faculty of Engineering Technology \\ University of Twente \\ Enschede 7500, AE, The Netherlands \\ E-mail: x.zeng@utwente.nl
}

DOI: 10.1002/adhm.201500067

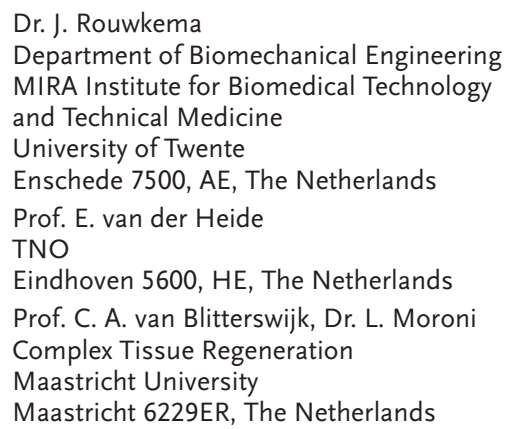

Maastricht 6229ER, The Netherlands 
3D fused deposition modeling (FDM) is an appealing additive manufacturing technique to fabricate scaffolds. The advantage of FDM is the high controllability and reproducibility of the scaffold's architecture, combined with a high flexibility in the pore network design. This results in an exquisite control of the physicochemical and mechanical properties presented to the cells used for tissue regeneration. ${ }^{[9]}$ Nevertheless, not only the biological response of the biomaterial should be taken into account. The application and design of a scaffold should also meet the functional requirements of the implantation-site environment. For instance, a scaffold for an osteochondral or chondral defect should provide minimal friction, but should still be able to withstand the mechanical load-bearing forces. Polycaprolactone (PCL), poly(lactic acid) (PLA), and their numerous derivatives are frequently used biomaterials for FDM. ${ }^{[10-13]}$ Both materials are FDA approved and have found clinical applications, for example as drug delivery vehicles and fixation screws. ${ }^{[9]}$ In addition to PCL and PLA, poly(ethylene oxide terephthalate)/poly(butylene terephthalate) (PEOT/PBT) is another class of copolymers that has been extensively studied by our group, among others. ${ }^{[14-16]}$ It has reached clinical applications as a cement stopper and a bone filler (PolyActive, Isotis Orthopaedics SA). ${ }^{[17-19]}$ Currently, clinical trials are being performed with PEOT/PBT scaffolds after obtaining promising results in preclinical studies. ${ }^{[20-22]}$

The biological performance of FDM scaffolds made from PCL, PLA, or PEOT/PBT has already been discussed in the literature with respect to skeletal regeneration. ${ }^{[10,13,15,16,23,24]}$ However, an in vitro comparison of cell-seeded FDM scaffolds from these biomaterials has not been performed and very few studies actually describe the tribological behavior of 3D scaffolds. In this respect, FDM offers not only the possibility to create 3D scaffolds with similar scaffold architecture and different biomaterial composition, but also the possibility to study the effect of scaffold architecture on the friction coefficient. Accardi et al. ${ }^{[25]}$ showed with electrospun scaffolds the influence of fiber orientation on friction and wear. Fibers with a unidirectional orientation in the shear loading direction showed less damage and wear than fibers with a random orientation. Moutos et al. ${ }^{[26,27]}$ and Liao et al. ${ }^{[28]}$ produced woven PCL scaffolds and coated them with fibrin to improve chondrogenesis. Although cartilage regeneration was proven successful, the influence of scaffold architecture and the effect of biomaterial on friction were not studied.

Therefore, in this study PCL, poly (L|DL) lactic acid (P(L|DL) LA), and PEOT/PBT FDM scaffolds were compared in terms of their in vitro biological and tribological performance. With the best performing tribological biomaterial, the relationship between scaffold architecture and friction coefficient was further investigated. The best and the worst scaffold architecture were chosen to investigate the effect of cell culture in 3D scaffolds on the friction coefficient. As this study shows, the tribological performance of a scaffold depends on the scaffold architecture, the biomaterial and the extracellular matrix formation. Therefore, we propose that when engineering articulating tissues such as cartilage, the resulting friction coefficient should be a determining factor for the design of the scaffold and the choice of the biomaterial.

\section{Results}

\subsection{Scaffold Characterization}

The fiber spacing of the scaffolds was set to be $1000 \mu \mathrm{m}$ for all biomaterials in the cell culture study. Results showed a fiber spacing of $965 \pm 38 \mu \mathrm{m}$ for PEOT/PBT, $980 \pm 22 \mu \mathrm{m}$ for PCL, and $942 \pm 40 \mu \mathrm{m}$ for P(L)DL)LA. Fiber diameter is dependent on the diameter of the needle used and was anticipated to be between 175 and $200 \mu \mathrm{m}$. For PEOT/PBT the fiber diameter was $186 \pm 20 \mu \mathrm{m}$, for PCL it was $169 \pm 9 \mu \mathrm{m}$, and for P(L|DL) LA it was $180 \pm 16 \mu \mathrm{m}$.

\subsection{Cell Localization and Extra Cellular Matrix (ECM) Formation in PCL, PEOT/PBT, and P(LIDL)LA}

Scanning electron microscopy (SEM) and methylene blue images showed good cell attachment and growth on all biomaterials (Figures 1 and $\mathbf{2}$ for basic medium and Supporting Information Figures S2-S5 for osteogenic and chondrogenic differentiation media). Homogeneous cell distribution was seen at each time point, for all media and biomaterials. Methylene blue images showed a rounded cell morphology for cellseeded scaffolds cultured in the chondrogenic differentiation medium (Figure S4, Supporting Information). SEM images showed ECM formation inside the scaffold, which increased with time to fill up the pores of the scaffold (Figure 2). Cellseeded scaffolds cultured in the osteogenic differentiation medium seemed to support the most ECM formation, while scaffolds cultured in the chondrogenic differentiation medium had the least ECM formation.

\subsection{Differentiation of Cells on the Biomaterials}

Alkaline phosphatase (ALP)/DNA showed the highest results for cell seeded on PCL and PEOT/PBT scaffolds (Figure 3A). For P(L)DL)LA, ALP activity quantification showed a significantly lower expression at every time point. The ALP activity/ DNA values were statistically significant higher for PEOT/PBT than PCL for osteogenic and chondrogenic differentiation for days 14 and 28. Additionally, the value for ALP activity/DNA was statistically significant higher for PEOT/PBT and PCL scaffolds cultured in the chondrogenic differentiation medium compared to scaffolds cultured in the basic and osteogenic differentiation media at days 14 and 28.

ALP staining corroborated the biochemical analysis for PCL and PEOT/PBT (Figures S6-S8, Supporting Information). The staining was positive for cell-seeded scaffolds cultured in the osteogenic differentiation medium in the case of PCL and PEOT/PBT at days 14 and 28 (Figure S7, Supporting Information). For $\mathrm{P}(\mathrm{L} \mid \mathrm{DL}) \mathrm{LA}$ the staining was positive at day 28 when cultured in the osteogenic medium, thus showing that despite of a lack of ALP activity the protein was produced by the cells. Interestingly, when cell-seeded PCL scaffolds were cultured in the chondrogenic differentiation medium, ALP staining was more intense at all time points compared to the osteogenic differentiation medium (Figures S6 and S7, Supporting 


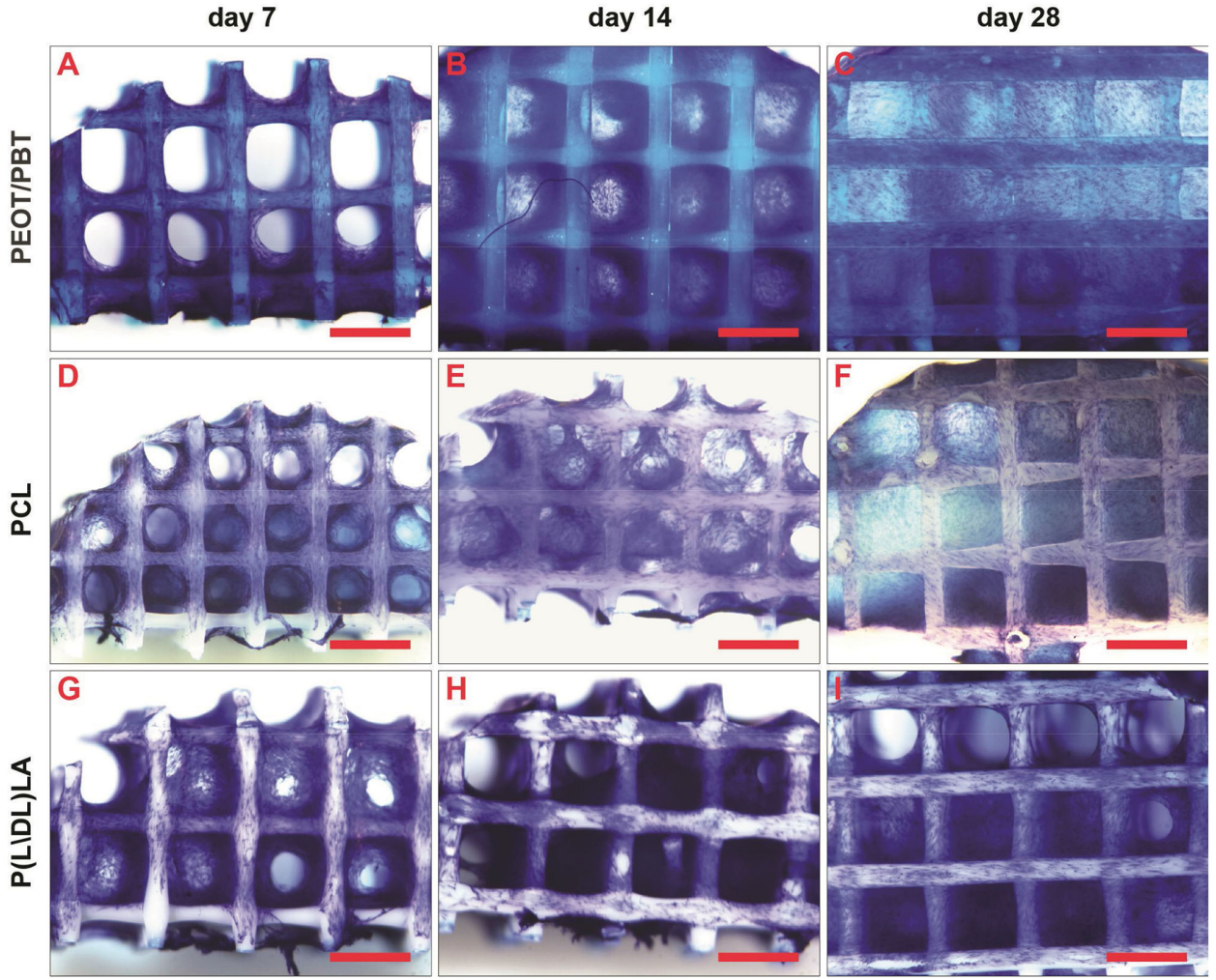

Figure 1. Methylene blue images of cell-seeded scaffolds cultured in the basic medium showed good cell attachment and ECM deposition in A-C) PEOT/PBT scaffolds, D-F) PCL scaffolds, and G-I) P(L\DL) LA scaffolds. Methylene blue images for osteogenic and chondrogenic differentiation media can be found in the Supporting Information. Scale bar is $1000 \mu \mathrm{m}$.

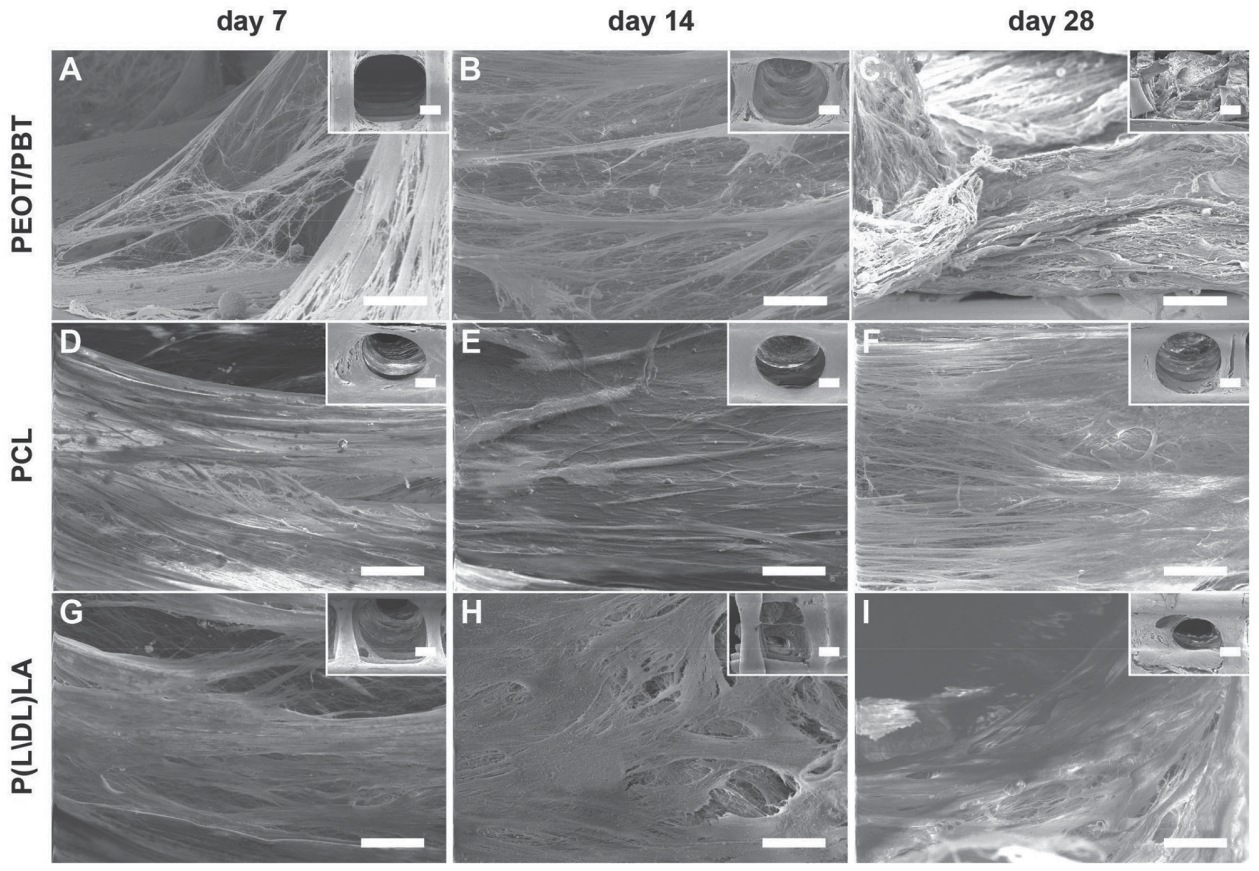

Figure 2. SEM images of cell-seeded scaffolds cultured in the basic medium showed good cell attachment and ECM deposition in A-C) PEOT/PBT scaffolds, D-F) PCL scaffolds, and G-I) P(L\DL) LA scaffolds. SEM images for osteogenic and chondrogenic differentiation media can be found in the Supporting Information. Scale bar is 100 and $200 \mu \mathrm{m}$ for the inset. 


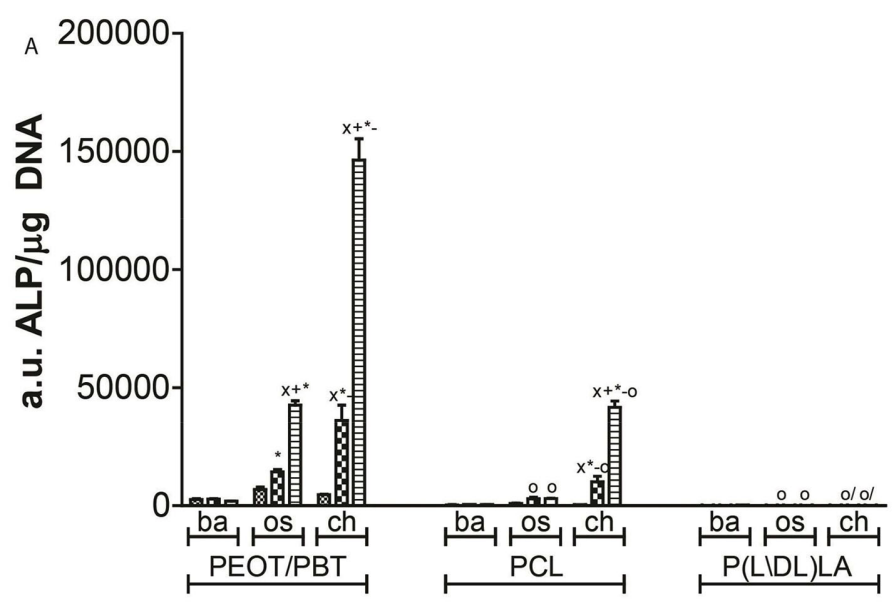

B

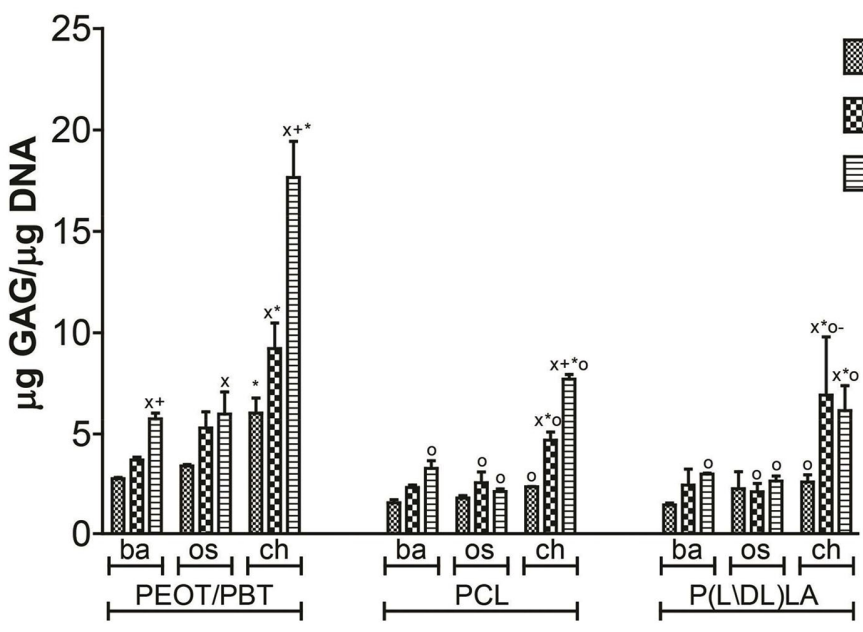

Figure 3. An increase of A) ALP/DNA and B) GAG/DNA with culture time for PEOT/PBT, PCL, and $P(L \mid D L) L A$ cell-seeded scaffolds cultured in basic (ba), osteogenic (os), and chondrogenic (ch) differentiation media was measured. The coupling of high ALP/DNA with GAG/DNA for the chondrogenic medium suggests hypertrophic differentiation $(x$ : statistically significant different from day $7 ;+$ : statistically significant different from day 14 ; o: statistically significant different from PEOT basic for the same media and time point; *: statistically significant difference from basic and osteogenic media at the same time point and the same material; and -: statistically significant difference from PCL in the chondrogenic medium at day 14). value compared to the basic and osteogenic culture condition at all time points, except day 7 for PCL and P(L\DL)LA. PEOT/PBT had the highest values for all conditions with a maximum of $17.65 \pm 1.95 \mu \mathrm{g}$ GAG/ $\mu \mathrm{g}$ DNA at day 28. PCL and P(L $\backslash$ DL)LA had similar levels when cultured in basic and osteogenic differentiation media. In the chondrogenic differentiation medium, PCL had a slightly higher GAG/DNA than P(L DL)LA at day $28(7.71 \pm 0.43$ vs $6.16 \pm 1.10 \mu \mathrm{g}$ GAG/ $\mu \mathrm{g}$ DNA), while at day $14 \mathrm{P}(\mathrm{L} \backslash \mathrm{DL}) \mathrm{LA}$ was higher $(6.93 \pm 2.53$ vs $4.69 \pm 0.39 \mu \mathrm{g}$ GAG/ $\mu$ g DNA) When cell-seeded scaffolds were cultured in basic and osteogenic differentiation media, the levels were low and reached at day 28 the same value as on day 7 for cells cultured in the chondrogenic differentiation medium.

\subsection{The Effect of Biomaterials on the Tribological Behavior of the Scaffolds}

The friction of the same architectural scaffolds (fiber spacing $600 \mu \mathrm{m}$ and $90^{\circ}$ angle between layers) was measured with either PCL, P(L $\backslash D L) L A$, or PEOT/PBT as the scaffold biomaterial. The tribological tests were conducted at $2.0 \mathrm{~mm} \mathrm{~s}^{-1}$ under 0.15 and $1.00 \mathrm{~N}$, respectively. After $\approx 10-30$ rotations, the friction coefficient reached equilibrium (Figure S9, Supporting Information). Under all test conditions, the friction coefficient was the highest in $\mathrm{P}(\mathrm{L} \mid \mathrm{DL}) \mathrm{LA}$ followed by PCL and PEOT/PBT (Figure 4). Statistical analysis indicated that the friction coefficient of $\mathrm{P}(\mathrm{L})$ DL)LA scaffolds was significantly higher than that of PCL and PEOT/PBT, and the friction coefficient of PCL scaffolds was significantly higher than that of PEOT/PBT as well.
Information). For PEOT/PBT the staining was positive as well for all time points in the chondrogenic medium, while for $\mathrm{P}(\mathrm{L})$ DL)LA the staining was negative or weak. Scaffolds cultured in basic medium showed a weak or negative staining for all time points for all biomaterials (Figure S6, Supporting Information).

To assess chondrogenic differentiation, glycosminoglycans (GAG) production was measured. All biomaterials supported chondrogenic differentiation, as observed by the rounded cell morphology in the methylene blue staining (Figure S4, Supporting Information). GAG/DNA increased over time for all biomaterials when cultured in the chondrogenic differentiation medium (Figure 3B). PEOT/PBT scaffolds had statistically significant higher values at all time points when cultured in the chondrogenic medium, at days 14 and 28 for osteogenic differentiation and at day 28 for basic medium compared to both PCL and P(L $\mid \mathrm{DL}) \mathrm{LA}$. The chondrogenic culture condition in all biomaterials had a statistically significant higher GAG/DNA

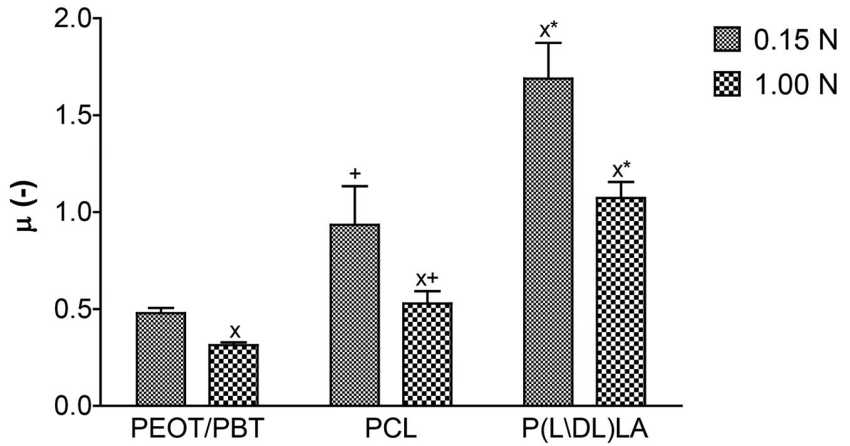

Figure 4. Friction coefficient of PEOT/PBT, $P C L$, and $P(L \mid D L) L A$ at $0.15 \mathrm{~N}$ and $1.00 \mathrm{~N}$ load applied and $2.0 \mathrm{~mm} \mathrm{~s}^{-1}$ sliding velocity. An increased applied load decreases the friction coefficient in all materials. $(x$ : statistically significant different from tests under $0.15 \mathrm{~N}$ for the same material; +: statistically significant different from PEOT/PBT under the same normal load; *: statistically significant different from $\mathrm{PCL}$ under the same normal load). 

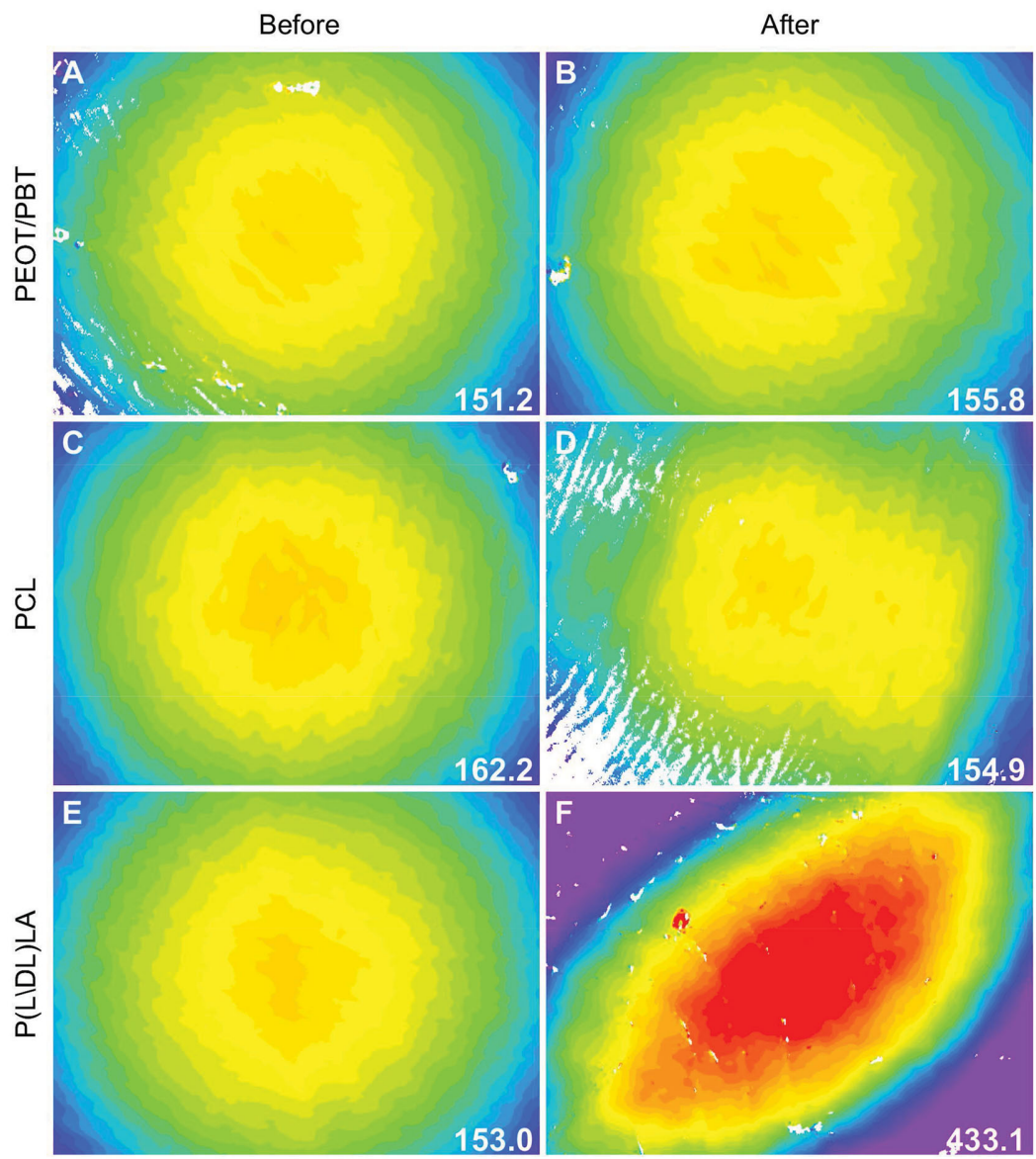

$600.0 \mathrm{~nm}$
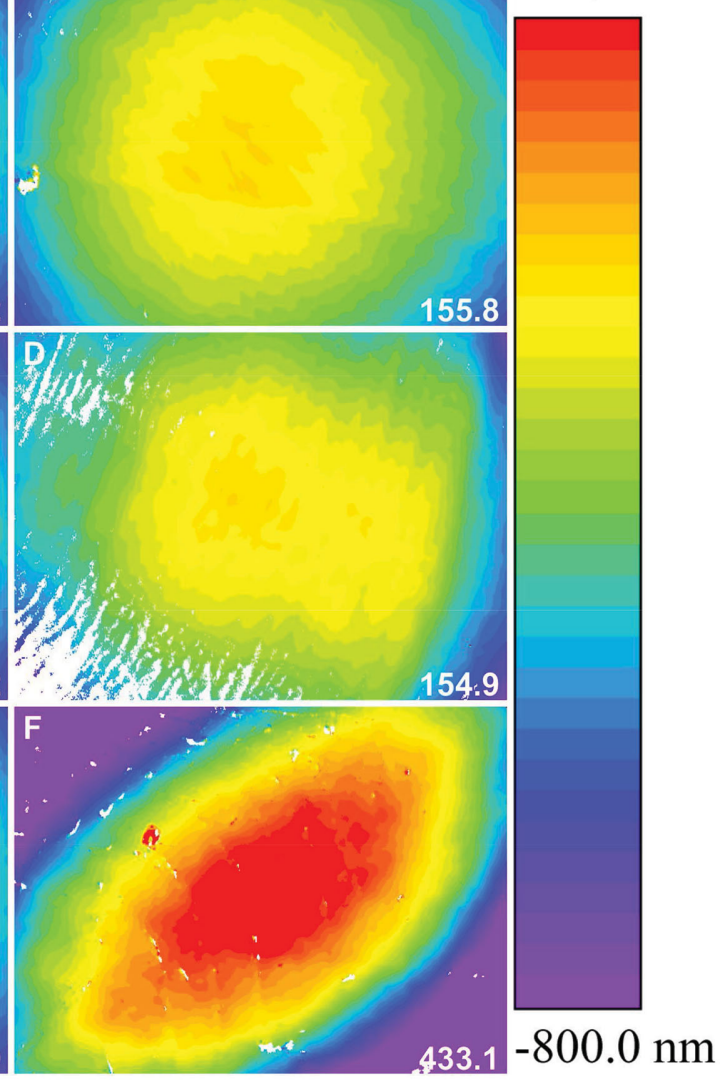

Figure 5. Spherical cap surface [Image: topography (40X); Number: roughness (Sa, nm)] at $1.00 \mathrm{~N}$ and $2.0 \mathrm{~mm} \mathrm{~s}^{-1}$ for $\left.\left.A, B\right) P E O T / P B T, C, D\right) P C L$, and $E, F) P(L \mid D L) L A$ before and after conducting a measurement. When testing with $P(L \backslash D L) L A$, the counter surface shows a high deformation after conducting a measurement, while for PEOT/PBT almost no differences were observed.

When the applied force increased from 0.15 to $1.00 \mathrm{~N}$ the friction coefficient decreased from $0.479 \pm 0.027$ to $0.314 \pm 0.014$ for PEOT/PBT, from $0.935 \pm 0.200$ to $0.529 \pm 0.064$ for PCL, and from $1.689 \pm 0.185$ to $1.073 \pm 0.083$ for $\mathrm{P}(\mathrm{L} \mid \mathrm{DL}) \mathrm{A}$. The surface topography and roughness of the counter surface (PU cap) before and after the tribological test $\left(1.00 \mathrm{~N}, 2.0 \mathrm{~mm} \mathrm{~s}^{-1}\right)$ are shown in Figure 5 and Figure S10 (Supporting Information). It can be seen that there was a slight change in the shape of the spherical cap after testing with PEOT/PBT. For PCL, the cap shape was changed obviously while the roughness was almost the same. However, for $\mathrm{P}(\mathrm{L} \mid \mathrm{DL}) \mathrm{LA}$, the roughness increased and the cap was significantly deformed. Based on the low friction coefficient and the low surface roughness on the PU cap after testing, PEOT/PBT was chosen as the biomaterial for further investigating the effect of scaffold architecture on the tribological performance.

\subsection{The Effect of Architecture on the Tribological Behavior of the Scaffolds}

The pore network architecture of the fabricated scaffolds was changed by varying either the pore size or the pore shape.
Scaffolds with different pore sizes were created by changing the fiber spacing from 600, to 800 and $1000 \mu \mathrm{m}$. For scaffolds with fiber spacing of $600 \mu \mathrm{m}$, the pore shape was changed by varying the angle between layers from $90^{\circ}$ to $45^{\circ}$. As seen previously, when the applied load increased from 0.15 to $1.00 \mathrm{~N}$, the friction coefficient decreased (Figure 6). With decreasing fiber spacing, the friction coefficient also decreased for all applied loads and velocities, from $0.531 \pm$ 0.050 for $1000 \mu \mathrm{m}$ to $0.314 \pm 0.014$ for $600 \mu \mathrm{m}$ at $1.00 \mathrm{~N}$ and $2.0 \mathrm{~mm} \mathrm{~s}^{-1}$. Furthermore, reducing the sliding velocity caused a decrease in friction coefficient, from $0.314 \pm 0.014$ for $600 \mu \mathrm{m}$ at $2.0 \mathrm{~mm} \mathrm{~s}^{-1}$ to $0.240 \pm 0.023$ for $600 \mu \mathrm{m}$ at $0.2 \mathrm{~mm} \mathrm{~s}^{-1}$. The scaffold architecture with a $45^{\circ}$ angle layer orientation had a statistically significant higher friction coefficient compared to the $90^{\circ}$ angle layer rotation, $0.649 \pm$ 0.056 for $45^{\circ}$ versus $0.479 \pm 0.027$ for $90^{\circ}$ subjected to a $0.15 \mathrm{~N}$ load and $2.00 \mathrm{~mm} \mathrm{~s}^{-1}$ sliding velocity. When a load of $1.00 \mathrm{~N}$ was applied, the $45^{\circ}$ scaffold failed. The lowest friction coefficients were achieved with increased loading and reduced sliding velocity. The best (600 $\mu \mathrm{m}$ fiber spacing) and the worst (1000 $\mu \mathrm{m}$ fiber spacing) architecture were chosen to further investigate the effect of cell culture on the friction coefficient. 


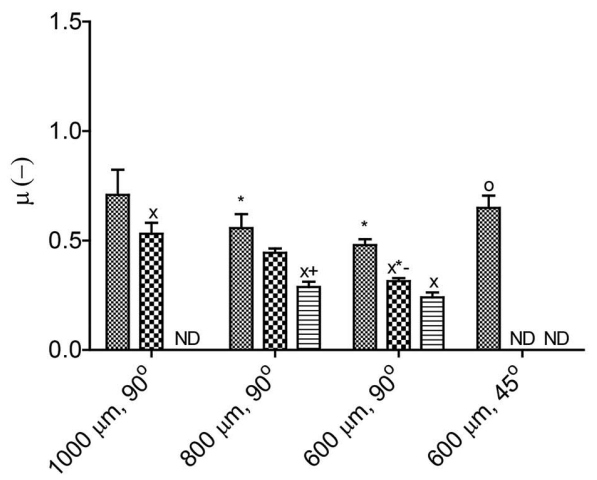

Figure 6. Influence of the PEOT/PBT scaffold architecture on friction coefficient at $0.15 \mathrm{~N}$ and $1.00 \mathrm{~N}$ load applied with a $2.0 \mathrm{~mm} \mathrm{~s}^{-1}$ sliding velocity and $1.00 \mathrm{~N}$ load applied with a $0.2 \mathrm{~mm} \mathrm{~s}^{-1}$ sliding velocity. An increased load resulted in a lower friction coefficient for all architectures. A decreased sliding velocity also resulted in a lower friction coefficient. A reduce in fiber spacing decreased the friction coefficient, and the change of fiber orientation from $90^{\circ}$ to $45^{\circ}$ increased the friction coefficient $(x$ : statistically significant different from tests under $0.15 \mathrm{~N}, 2.0 \mathrm{~mm} \mathrm{~s}^{-1}$ for the same architecture; +: statistically significant different from tests under $1.00 \mathrm{~N}, 2.0 \mathrm{~mm} \mathrm{~s}^{-1}$ for the same architecture; *: statistically significant different from architecture $1000 \mu \mathrm{m}$ under the same test conditions; -: statistically significant different from architecture $800 \mu \mathrm{m}$ under the same test conditions; and o: statistically significant different from architecture $600 \mu \mathrm{m}, 90^{\circ}$ under the same test conditions).

\subsection{The Effect of Cell Culture on the Tribological Behavior of the Scaffolds}

Since mainly articular cartilage is of interest with respect of tribological behavior, cells were cultured in basic medium and chondrogenic differentiation medium. The same time points as before were chosen to study tribological behavior and biological performance. In order to isolate the effect of matrix formed by the cells, scaffolds were not coated with collagen type I and hMSCs were not preincubated with fibronectin prior to seeding. SEM images showed low cell attachment and ECM formation inside the cell cultured scaffolds (Figure 7). No statistical differences were found between any groups. GAG content was low but production increased over time and showed to be the highest for cellseeded scaffolds cultured in the chondrogenic differentiation medium (Figure 8).

Increasing the applied force resulted in a statistically significant reduction in friction coefficient with a $2.0 \mathrm{~mm} \mathrm{~s}^{-1}$ sliding velocity (Figure 9A). With the same load of $1.00 \mathrm{~N}$, decreasing the sliding velocity from 2.0 to $0.2 \mathrm{~mm} \mathrm{~s}^{-1}$ did not result in a significant reduction of the friction coefficient (Figure 9B), as previously observed. Although at the beginning of the cell culture the $600 \mu \mathrm{m}$ fiber spacing scaffold performed better, at the end of the culture time (day 28) the $1000 \mu \mathrm{m}$ fiber spacing scaffold had a statistically significant lower friction coefficient. Scaffolds cultured in basic medium had generally a lower friction coefficient than the scaffolds cultured in chondrogenic differentiation medium. This trend was seen at the same sliding velocity of $2.00 \mathrm{~mm} \mathrm{~s}^{-1}$, but with varying load applied.

\section{Discussion}

In tissue engineering, scaffolds are used to regenerate diseased or damaged tissues. By exploiting scaffold's properties such as surface topography and chemistry, cells can be instructed to differentiate toward specific differentiation lineages. A scaffold design should have appropriate properties to meet the conditions to function at the implantation site. It is therefore important to know the biological effect of the biomaterial on cell culture. In the case of scaffolds for articular skeletal tissue applications, the friction is important as the environment of the implantation-site requires a smooth articulation. In the literature, not much attention has been given to the biological and tribological comparison between the same architectural scaffolds made from different biomaterials. Additionally, the effect of scaffold architecture on the friction has not been broadly investigated either.

In our study, scaffolds were made from either PEOT/PBT, $\mathrm{P}(\mathrm{L} \backslash \mathrm{DL}) \mathrm{LA}$, or PCL. The influence of the scaffold architecture and the effect of cell culture in different cell culture media on the friction coefficient were investigated. ALP activity/DNA, which is generally regarded as an indicator of osteogenic differentiation, increased with culture time when scaffolds were cultured in the osteogenic differentiation medium. Interestingly, it was the highest when cultured in the chondrogenic differentiation medium (Figure 3A). PEOT/PBT resulted in the highest GAG/DNA production with a maximum at day 28 for cell-seeded scaffolds cultured in the chondrogenic differentiation medium (Figure 3B). The high ALP activity values and the positive ALP staining imply that the formed chondrogenic ECM might be going toward hypertrophy. However, it is known that hMSCs induced to differentiate down the chondrogenic lineage have the tendency to go toward hypertrophic cartilage. ${ }^{[29,30]}$ Furthermore, scaffolds were coated with collagen type I, which is one of the main components of bone ECM. Therefore, such a collagen coating of the scaffold might have influenced the chondrogenic differentiation of the seeded hMSCs. In vivo bone formation can be through intramembranous or endochondral ossification. In the latter case, cartilage is formed first and then progresses toward bone. Although this might explain the results obtained, further investigation is needed to confirm if the observed enhancement of ALP in the chondrogenic medium can indeed be associated with endochondral ossification. Jeong and Hollister ${ }^{[24]}$ showed that PCL had a tendency to induce hypertrophy although they used chondrocytes and osteoblasts.

Cell-cultured scaffolds made from either PCL, PEOT/PBT, or $\mathrm{P}(\mathrm{L} \backslash \mathrm{DL}) \mathrm{LA}$ facilitated ECM deposition when the scaffolds were coated with collagen (Figures 1 and 2 and Figures S2-S5, Supporting Information). The highest ECM deposition was found in scaffolds cultured in the osteogenic differentiation medium, while the chondrogenic differentiation medium resulted in the lowest ECM deposition. Methylene blue staining showed rounded cell morphology for the chondrogenic differentiation medium. Combined with the high amount of GAG/DNA, this suggests chondrogenic differentiation in all scaffolds (Figure 3 and Figures S4 and S5, Supporting Information). Comparing the GAG/DNA values with other reported studies using hMSCs as cell source, the values reported in this study are higher (17.65 $\mu \mathrm{g}$ GAG/ $\mu \mathrm{g}$ DNA). 


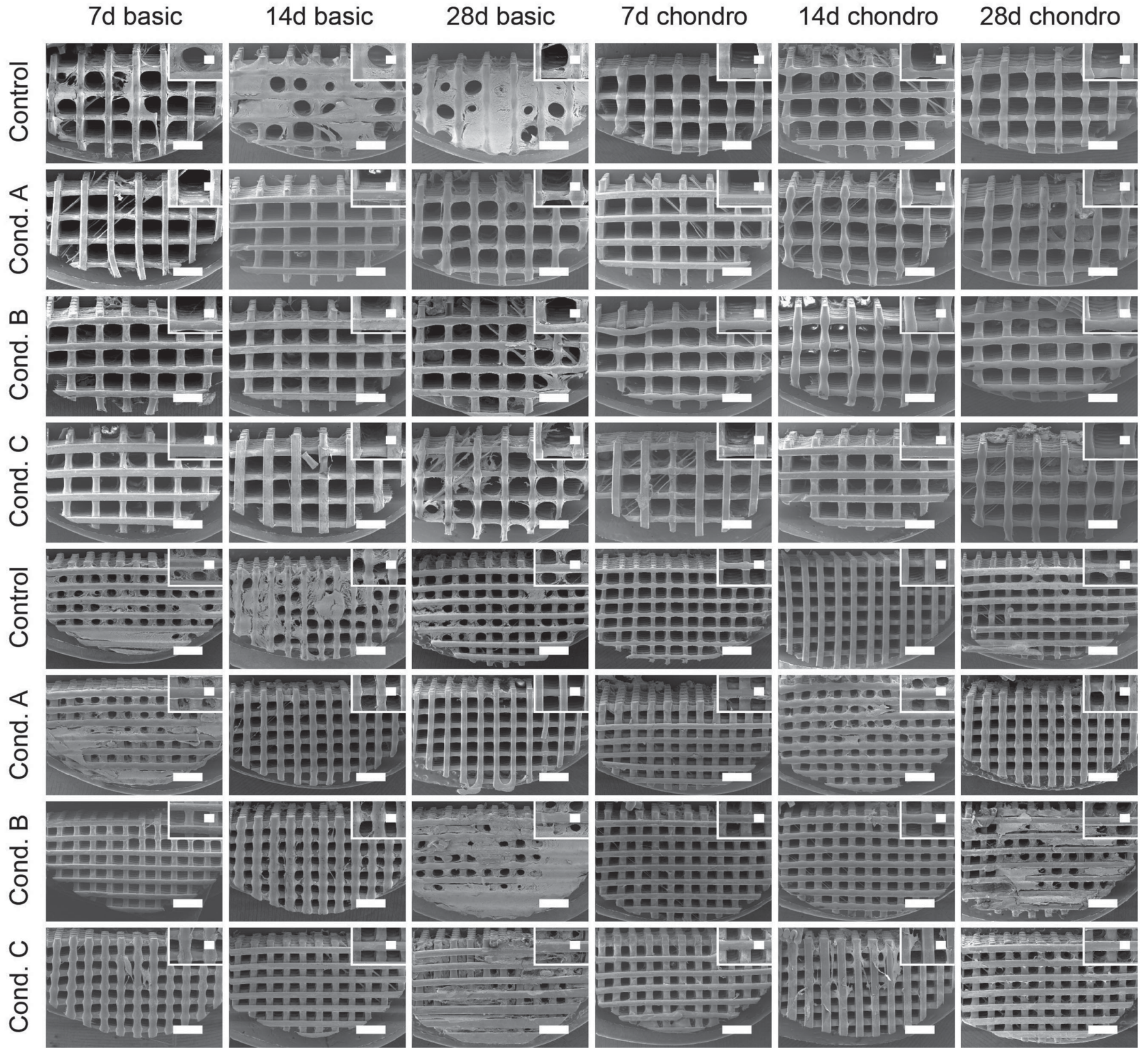

Figure 7. SEM images of cell-cultured PEOT/PBT scaffolds subjected to tribological testing. Condition $A$ is $0.15 \mathrm{~N}$ and $2.0 \mathrm{~mm} \mathrm{~s}^{-1}$, condition $\mathrm{B}$ is $1.00 \mathrm{~N}$ and $2.0 \mathrm{~mm} \mathrm{~s}^{-1}$ while condition $\mathrm{C}$ is $1.00 \mathrm{~N}$ and $0.2 \mathrm{~mm} \mathrm{~s}^{-1}$. The images show low cell attachment and ECM formation inside the cell-cultured scaffolds. Scale bars are 1000 and $200 \mu \mathrm{m}$ for the inset.

Wise et al. ${ }^{[31]}$ reported a value around $5 \mu \mathrm{g}$ GAG/ $\mu \mathrm{g}$ DNA on electrospun scaffolds, while the PLA constructs of Tuli et al. ${ }^{[32]}$ had a similar value.

From tribology analysis, it was found that PEOT/PBT scaffolds had the lowest friction coefficient of all the biomaterials tested (Figure 4). Therefore, PEOT/PBT was used to investigate the influence of scaffold architecture on the friction coefficient (Figure 6). A reduced friction coefficient was observed with decreased fiber spacing. Cell-cultured PEOT/PBT scaffolds with the best and the worst performing architecture showed a shifting trend with respect to the friction coefficient (Figure 9A,B). What was initially the best performing scaffold architecture, had the highest friction coefficient after 28 days of cell culture.
The scaffold has a porous structure and is made from a polymer. Polymers are viscoelastic and their properties depend on time in contrast to metals and ceramics. Sources of friction for polymers are mainly adhesion, deformation, and elastic hysteresis. It is expected that the deformation component will play a dominant role for the tribological performance of the porous polymer scaffold. ${ }^{[33]}$ The change in biomaterial results in a change of the intrinsic stiffness and, consequently, of the deformation. The friction coefficient of the scaffolds was the highest for $\mathrm{P}(\mathrm{L})$ DL)LA followed by PCL and PEOT/PBT (Figure 4), which is in good agreement with the intrinsic biomaterial stiffness $(\mathrm{P}(\mathrm{L} \mid \mathrm{DL})$ $\mathrm{LA} \approx 2-3 \mathrm{GPa}, \mathrm{PCL} \approx 0.4 \mathrm{GPa}$, and $\mathrm{PEOT} / \mathrm{PBT} \approx 0.1 \mathrm{GPa}) .{ }^{[34-36]}$

The dynamic or apparent stiffness of the scaffold is directly influenced by the scaffold architecture ${ }^{[34-36]}$ and will influence 


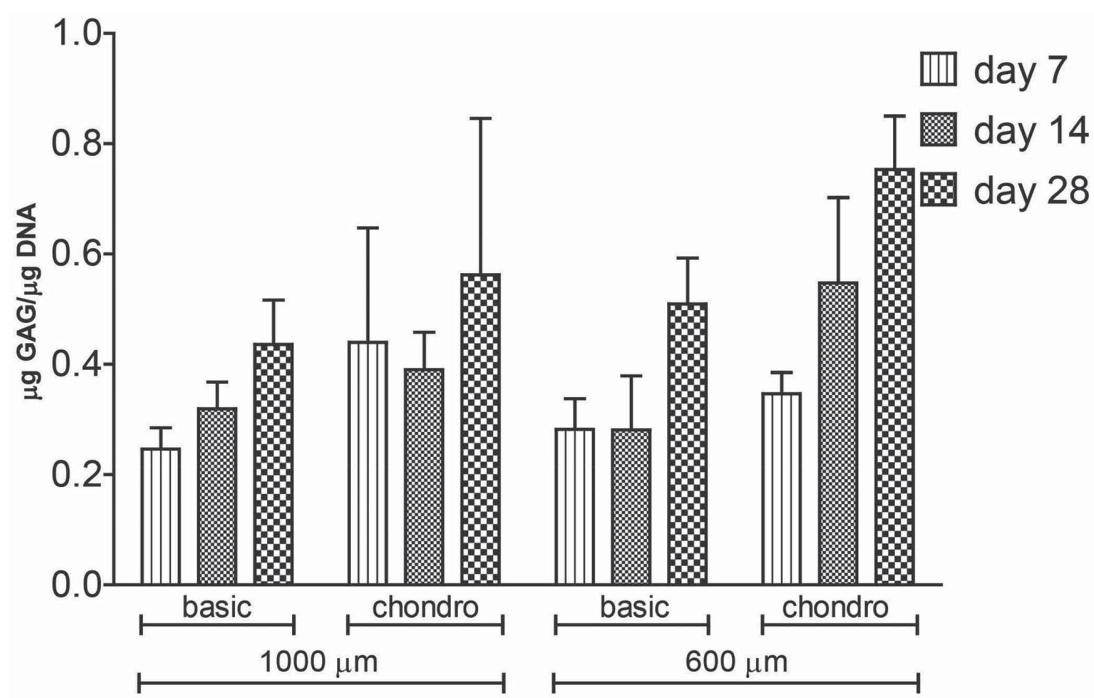

Figure 8. GAG/DNA $(\mu \mathrm{g} / \mu \mathrm{g})$ of the cell-seeded PEOT/PBT scaffolds cultured in basic and chondrogenic differentiation media. The GAG/DNA ratio increased with culture time; however, no statistical differences were found.

the deformation as well. The dynamic stiffness of the PEOT/ PBT scaffold used here (600 $\mu \mathrm{m}$ fiber spacing) is similar to that of the PU cap. ${ }^{[31]}$ Since the intrinsic biomaterial stiffness of P(L|DL)LA and PCL is higher than that of PEOT/PBT, it is expected that the dynamic stiffness of the P(L $\mid \mathrm{DL}) \mathrm{LA}$ and PCL scaffolds will therefore be higher than that of the PU cap as well. During the tribological tests, the softer PU cap is therefore expected to be more deformed at this test condition. The deformation can be deduced from the changes in morphology of the counter surface before and after the tribological test (Figure 5). PEOT/PBT was chosen as the biomaterial to investigate the effect of scaffold architecture on the friction coefficient since it had the lowest friction values. The dynamic stiffness of the PEOT/PBT scaffold is similar to $(600 \mu \mathrm{m}$ fiber spacing) or lower than (800 and $1000 \mu \mathrm{m}$ fiber spacing) that of the PU cap. Therefore, at this test condition the scaffold is expected to be deformed instead of the PU cap. When analyzing the effect of scaffold architecture on friction, reducing the fiber spacing resulted in a reduced friction coefficient. With reducing of the fiber spacing, on the one hand, the real contact area increases, leading to an increase of the adhesion component of the friction. On the other hand, with reducing of fiber spacing the apparent dynamic stiffness of the scaffold is known to increase. ${ }^{[34-36]}$ This makes the scaffold less deformable, resulting in the decrease of the deformation component of the friction. Since the friction coefficient decreases with the reducing of fiber spacing, it is further confirmed that the deformation component plays the dominant role in the tribological performance of porous polymer scaffolds. Changing the angle of orientation between successive layers decreased the apparent stiffness of the scaffold to such an extent that at the high load of $1.00 \mathrm{~N}$ the scaffold mechanically failed.

As for the influence of the applied load, with the increasing of the load the friction coefficient decreased (Figures 4 and 6). As described by Myshkin et al., ${ }^{[37]}$ the friction of polymers as a function of load varies depending on the applied normal load. That is, the friction coefficient passes a minimum, which corresponds to transition from elastic to plastic contact. The test results indicate that under the tested normal load, the scaffolds elastically deformed. During elastic deformation, the real contact area $(\mathrm{Ar})$ increases less proportionally with the normal load (Fn), causing the friction coefficient to decrease under higher load. In addition, from Figure 6 it can also be found that with the reducing of fiber spacing, the friction coefficient decreased. As described before, the decrease in fiber spacing resulted in increased scaffold stiffness. The higher the stiffness is, the less real contact area change can be expected with the increasing of normal load, thus leading to a further decrease of the friction coefficient.

When looking at the influence of sliding velocity (Figure 6), the friction coefficient increased with the increasing of sliding velocity. This was more pronounced for the scaffold with larger fiber spacing which had a lower apparent stiffness. At a higher rotating velocity, the scaffold has less relaxation time to reorder its structure after elastic deformation. The recovery of the scaffold deformation cannot keep up with the sliding velocity. Therefore, it is likely that the spherical cap passed the former deformation region of the scaffold and further deformed it, consequently increasing the friction coefficient. ${ }^{[30]}$

The architectures with the lowest (600 $\mu \mathrm{m}$ fiber spacing) and the highest friction coefficient (1000 $\mu \mathrm{m}$ fiber spacing) were chosen to study the effect of cell culture on the friction coefficient. Again, the friction coefficient increased with increasing force and speed as observed in the previous tribological experiments. Interestingly, the best performing architecture shifted from having the lowest friction coefficient to the highest friction coefficient during the 28 days of culturing. Since the materials and geometries of the scaffolds are unlikely to change during the experiment, this effect is most likely due to the ECM formed on the scaffolds. As the $1000 \mu \mathrm{m}$ fiber spacing scaffolds display less ECM formation compared to the $600 \mu \mathrm{m}$ fiber spacing scaffolds (Figure 7), this finding might suggest that in vitro ECM formation by hMSCs is not beneficial for reducing the friction coefficient. SEM pictures showed a consistent higher amount of ECM in the controls than in the scaffolds subjected to tribological testing. Despite the fact that during the tribological testing the applied force is generally low, it might not be excluded that this is sufficient to dislodge the ECM from the scaffolds. The low and varying amount of ECM seen in the scaffolds for the tribological experiments (Figure 7) might have resulted in the lack of statistical differences found for GAG/ DNA (Figure 8).

As discussed in the literature, the test setup influences the value of the friction coefficient severely. ${ }^{[38,39]}$ From articular cartilage explants the role of sliding velocity, contact area, and lubrication was investigated. ${ }^{[38-43]}$ Combinations of contact pressure, velocity, and viscosity (Hersey number) results in different lubrication modes which can be related to the friction 


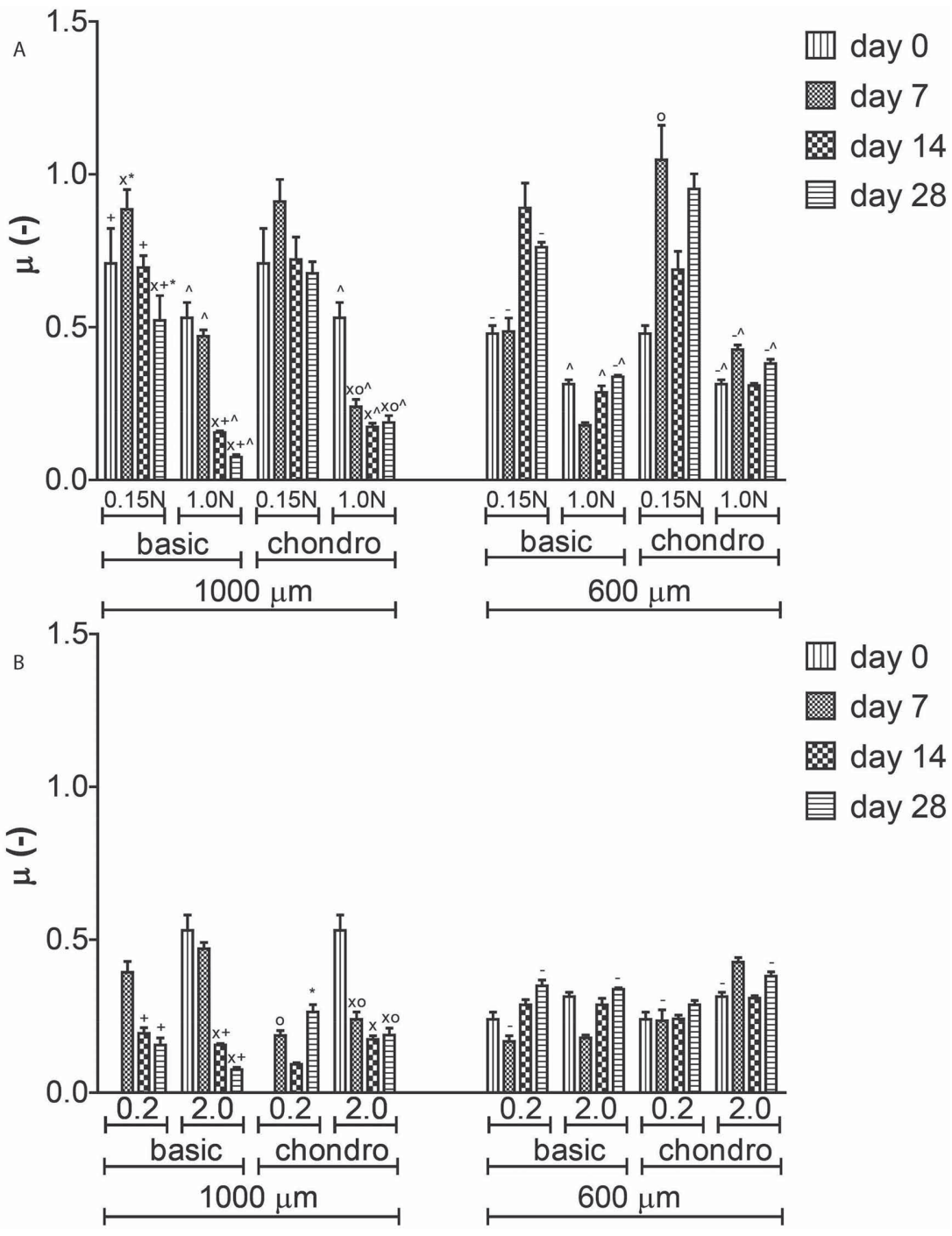

Figure 9. Friction coefficient of cell-cultured PEOT/PBT scaffolds for $0.15 \mathrm{~N}$ and $1.00 \mathrm{~N}$ applied load at A) $2.0 \mathrm{~mm} \mathrm{~s}^{-1}$ sliding velocity, B) 0.2 and $2.0 \mathrm{~mm} \mathrm{~s}$-1 sliding velocities with $1.00 \mathrm{~N}$ load. Increasing the load led to a decreased friction coefficient. However, the decreased sliding velocity did not decrease the friction coefficient as seen previously. Scaffolds cultured in the basic medium had generally a lower friction coefficient than the scaffolds cultured in the chondrogenic differentiation medium ( $\times$ : statistically significant different from day 0 for the same media and the same test conditions; + : statistically significant different from day 7 for the same media and the same test conditions; *: statistically significant different from day 14 for the same media and the same test conditions; -: statistically significant different from architecture $1000 \mu \mathrm{m}$ for the same media under the same test conditions; o: statistically significant different from the basic medium for the same architecture under the same test condition; ${ }^{\wedge}$ : statistically significant different from tests under $0.15 \mathrm{~N}$ normal load for the same media and the same architecture in $(A) ;{ }^{\wedge}$ : statistically significant different from tests under $0.2 \mathrm{~mm} \mathrm{~s}^{-1}$ velocity for the same media and the same architecture in (B).

coefficient by the Stribeck curve. ${ }^{[39]}$ These studies showed that interstitial fluid support is to a large extent responsible for low friction coefficients. ${ }^{[40,42]}$ However, Shi et al. ${ }^{[38]}$ showed through a pin-on-disk setup that the material choice on the pin and disk also influenced the results significantly. The migrating contact area enabled to replenish the cartilage with fluid again to obtain interstitial fluid support throughout the entire experiment. If the tissue is allowed to replenish with fluid, the friction coefficient is significantly lowered as the load is supported by fluid. When the fluid is expelled and not allowed to replenish, the load is supported by the solid part of the ECM, resulting in a higher friction coefficient. Whether one of the two conditions or a combination of the two conditions is achieved depends on the test setup. The ballon-pin setup used in our study in combination with the polymeric scaffold resulted in the load supported by the solid material, thus giving a high friction coefficient. Additionally, the tribological tests were performed with the scaffolds immersed in phosphate buffer saline (PBS), which is not a representative lubrication fluid like synovial fluid. The friction coefficient of bovine articular cartilage is reported between 0.1 and $0.02^{[41,42]}$ and for human cartilage between 0.06 and 0.15 for a variety of experimental settings. ${ }^{[4]}$ Despite the difficulty in comparing our results with known values in the literature for native cartilage due to the influence of different test setups, we can infer that our obtained friction coefficients are still indicative of a nonfully matured hyaline cartilaginous tissue. In our test setup, the PU ball is stationary and the scaffold is in a rotational motion. However, in knee articulation the motion is a complex combination of sliding and rolling which will be difficult to reproduce in vitro. We used PBS as lubrication, but from the literature it is known that PBS increases the friction coefficient. ${ }^{[39]}$ The friction coefficient in vivo will be lower compared to the test setup used in this study due to the lubrication.

Currently, research of tribological and biological behavior of the interplay between scaffold biomaterial and architecture is limited. Here, we present a study on the effect of scaffold biomaterial on the friction coefficient. Results showed significant differences between commonly used biomaterials, fabricated with the same additive manufacturing technique. The benefit of using FDM is the ability to control the scaffold architecture and use different biomaterials. FDM enables to investigate systematically the effect of scaffold architecture on the friction coefficient. Here, the effect of cell culture on scaffolds showed a surprising result as the initially best architecture performed the least at the end of the culture period. Further research is needed to investigate if cell culture in polymeric scaffolds would be beneficial for the friction coefficient when employed for articular cartilage regeneration. It would be interesting to investigate in further studies the effect of ECM compositions produced by different cell types, tissue sources, or co-cultures on the tribological behavior of the final constructs. By changing the applied load and sliding to a more 
physiological setting, current and future medical intervention possibilities could be investigated for their prospective behavior. Scaffold design could be optimized for the patients benefit and this study is a very first step in developing such a system.

\section{Conclusion}

In this study, a comparison between scaffolds fabricated from different biomaterials has been made on their biological and tribological behavior. All scaffolds had good cell attachment and supported ECM formation when cultured in the basic, osteogenic, or chondrogenic differentiation medium. PEOT/PBT had a higher GAG/DNA production compared to the PCL and P(L) DL)LA. However, cell-seeded scaffolds cultured in the chondrogenic medium had high ALP activity signals and had positive ALP staining suggesting a possible hypertrophic differentiation. Tribological testing without cell culture showed PEOT/ PBT as the best performing biomaterial with respect to PCL and $\mathrm{P}(\mathrm{L} \mid \mathrm{DL}) \mathrm{LA}$. From the scaffold architecture investigation, it was shown that reducing fiber spacing reduced the friction coefficient. Reducing the layer orientation angle resulted in the scaffold mechanically failing. The best and worst scaffold architectures were used to investigate the effect of cell culture on the friction coefficient. Results did not show a beneficial effect of ECM formation in cell-seeded polymeric scaffolds. Cell-seeded scaffolds cultured in the basic medium had a consistent lower friction coefficient than cell-seeded scaffolds cultured in the chondrogenic differentiation medium. This study shows that the effect of scaffold architecture, biomaterial, and ECM formation plays a crucial role in the tribological behavior of the constructs.

\section{Experimental Section}

Scaffold Fabrication: Scaffolds were fabricated by a bioscaffolder (SYSeng, Germany), as previously described. ${ }^{[21]}$ Briefly, granules of either PCL $\left(M_{\mathrm{w}} 65000\right.$, Sigma), or $\mathrm{P}(\mathrm{L} \backslash \mathrm{DL})$ LA which is $80 / 20$ molar ratio of L-lactide to DL-lactide (Purasorb PLDL 8038, Purac), or the block copolymer 300PEOT55PBT45 (PolyVation B.V.) were inserted in the cartridge of the machine and heated to $190-200^{\circ} \mathrm{C}$. An applied nitrogen pressure of 5 bar and an auger screw system rotating at 200 RPM extruded the molten polymer through a $250 \mu \mathrm{m}$ diameter needle (DL technology) on a stationary platform. Scaffolds were fabricated through a layer-by-layer deposition, in which the angle between layers, fiber spacing, and layer thickness could be set while the fiber diameter depended on the needle size chosen. Scaffold blocks of $30 \times 30 \times 2.1 \mathrm{~mm}$ were created with a fiber diameter of 175-200 $\mu \mathrm{m}$, a layer thickness of $150 \mu \mathrm{m}$, a fiber spacing of $600 \mu \mathrm{m}$, and a $90^{\circ}$ angle between layers for the biological and tribological comparison of all the biomaterials (Table 1). For PEOT/PBT, additional scaffold blocks were made with either 1000,800 , or $600 \mu \mathrm{m}$ fiber spacing, or a layer orientation of $45^{\circ}$ angle (600 $\mu \mathrm{m}$ fiber spacing) between layers for determining the effect of scaffold architecture on the friction coefficient. Cylindrical scaffolds of $8 \mathrm{~mm}$ in diameter were obtained by using a biopsy puncher (Miltex). The actual fiber spacing and fiber diameter were measured for all three biomaterials by Image). SEM images were loaded and five random measurements were taken for each picture, thus 15 in total for each biomaterial, and the average was calculated.

Cell Culture: Bone marrow aspirates were obtained from patients after written informed consent. hMSCs were isolated and proliferated as described previously. ${ }^{[46]}$ The basic medium consisted of $\alpha$-MEM
(Gibco) supplemented with $10 \%$ fetal bovine serum (FBS) (Lonza), $0.2 \times 10^{-3} \mathrm{M}$ L-Ascorbic acid (Sigma), $2 \times 10^{-3} \mathrm{M}$ L-glutamine (Gibco), $100 \mathrm{U} \mathrm{mL}^{-1}$ penicillin (Life Technologies), and $100 \mu \mathrm{g} \mathrm{mL}^{-1}$ streptomycin (Life Technologies). Proliferation medium was the basic medium supplemented with $1 \mathrm{ng} \mathrm{mL}^{-1}$ bFGF (Instruchemie). The osteogenic differentiation medium consisted of the basic medium supplemented with $10 \times 10^{-9} \mathrm{M}$ dexamethasone (Sigma). The chondrogenic differentiation medium consisted of high glucose D-MEM (Gibco, Netherlands) supplemented with $50 \mathrm{mg} \mathrm{mL}^{-1}$ ITS pre-mix (BD biosciences), $50 \mathrm{mg} \mathrm{mL}^{-1} \mathrm{~L}$-Ascorbic acid (Sigma), $100 \mathrm{mg} \mathrm{mL}^{-1}$ sodium pyruvate (Sigma), $100 \mathrm{U} \mathrm{mL}^{-1}$ penicillin (Invitrogen), $100 \mu \mathrm{g} \mathrm{mL}$

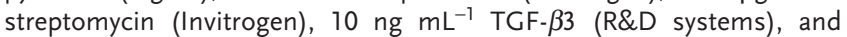
$0.1 \times 10^{-9} \mathrm{M}$ dexamethasone, which were freshly added every time that medium was changed. Cells were grown up to $80 \%-90 \%$ confluency at $37{ }^{\circ} \mathrm{C}$ in a humidified atmosphere with $5 \% \mathrm{CO}_{2}$. Passage 3 cells were used for all experiments.

Cell Culture on Scaffolds: Scaffolds were sterilized by immersion in $70 \%$ ethanol, twice for at least $15 \mathrm{~min}$, and were subsequently washed with PBS. The sterile scaffolds were immersed in a $1 \mathrm{mg} \mathrm{mL}^{-1}$ rat tail collagen type I (BD biosciences) solution overnight in a cell culture incubator. Scaffolds were washed with PBS and dried with the aspiration pump shortly before seeding $500000 \mathrm{hMSC}$ per scaffold in $65 \mu \mathrm{L}$ proliferation medium. hMSCs for chondrogenic differentiation were preincubated with $0.3 \mathrm{mg} \mathrm{mL}^{-1}$ fibronectin (Invitrogen) for $15 \mathrm{~min}$ before seeding. After seeding, cells were allowed to attach to the scaffold surface for $4 \mathrm{~h}$ before adding proliferation medium to $2 \mathrm{~mL}$ per scaffold. All scaffolds were cultured in proliferation medium for $7 \mathrm{~d}$ before changing to either the basic, osteogenic, or chondrogenic differentiation medium. Scaffolds were removed from cell culture after 7, 14, and $28 \mathrm{~d}$ cultured in differentiation media. At each time point, three scaffolds were collected for biochemical analysis, 1 for histology and 1 for microscopy. Every other day the medium was refreshed. The cell-seeded scaffolds were placed in an incubator at $37^{\circ} \mathrm{C}$ in a humidified atmosphere with $5 \% \mathrm{CO}_{2}$.

ALP/DNA and GAG/DNA: Cell-cultured scaffolds $(N=3)$ were cut in half for either ALP/DNA (A.U/ $/ \mu$ g) quantification or GAG/DNA $(\mu \mathrm{g} / \mu \mathrm{g})$ quantification. Each half was cut in as small pieces as possible and subjected five times to a cycle of freeze-thawing before analysis.

Cell lysis buffer $\left(0.1 \mathrm{M} \mathrm{KH}_{2} \mathrm{PO}_{4}, 0.1 \mathrm{M} \mathrm{K}_{2} \mathrm{HPO}_{4}, 0.1 \%\right.$ Triton $\mathrm{X}-100, \mathrm{pH}$ 7.8) was added to the cut samples and incubated for $1 \mathrm{~h}$ at room temperature before ALP or DNA quantification. ALP activity was quantified from the lysate according to the manufacturer's protocol (CDP-star Chemiluminescent substrate kit, Roche) with a VICTOR plate reader (Perkin Elmer).

The other half of the cell-cultured scaffold was digested in $1 \mathrm{mg} \mathrm{mL}^{-1}$ proteinase $\mathrm{K}$ (Sigma) in Tris/ethylenediaminetetraacetic (EDTA) ( $\mathrm{pH} 7.6)$ containing $18.5 \mu \mathrm{g} \mathrm{mL}^{-1}$ iodoacetamide (Sigma) and $1 \mu \mathrm{g} \mathrm{mL}^{-1}$ Pepstatin A (Sigma) for $16 \mathrm{~h}$ at $56^{\circ} \mathrm{C}$. Sulfated GAG content was spectrophotometrically determined immediately after adding 9-dimethylmethylene blue dye (DMMB, $3.04 \mathrm{~g} \mathrm{~L}^{-1}$ glycine, $2.37 \mathrm{~g} \mathrm{~L}^{-1}$ of $\mathrm{NaCl}, \mathrm{pH}=3$ ) at an absorbance of $525 \mathrm{~nm}$ in a Multiskan Go (Perkin Elmer). The amount of GAG was determined using a calibration curve of chondroitin sulfate.

Total DNA content was determined, on either lysate, following the manufacturer's protocol (CyQuant Cell proliferation assay kit). ALP and GAG were corrected by their total DNA content.

Methylene Blue and ALP Staining: Cell-seeded scaffolds were washed with PBS and fixated by $10 \%$ buffered formalin for $1 \mathrm{~h}$. Scaffolds were cut in half and one part was used for methylene blue and the other for ALP staining. A drop of $1 \%$ methylene blue solution was applied to the scaffold for a minute. The stained scaffold was washed with demineralized water until there was no more discoloring of the water. Samples were imaged with a Nikon SMZ-10A stereomicroscope equipped with a Sony 3CCD camera.

ALP staining was conducted with the Leukocyte Alkaline Phosphatase kit (Sigma) following the manufacturer's protocol. The remaining halves of the scaffolds were incubated with the fresh prepared alkaline dye for $30 \mathrm{~min}$, after which the scaffolds were washed with demineralized water and imaged with a Nikon stereomicroscope. 
Table 1. Scaffold and tribological parameters used per study. Ba: basic medium; Os: osteogenic medium; and Ch: chondrogenic medium.

\begin{tabular}{|c|c|c|c|c|c|}
\hline & Spacing $[\mu \mathrm{m}]$ & Orientation $\left[{ }^{\circ}\right]$ & Load [N] & Speed $\left[\mathrm{mm} \mathrm{s}^{-1}\right]$ & Medium \\
\hline \multicolumn{6}{|l|}{ Biological } \\
\hline РEOT/PBT & 1000 & 90 & - & - & $\mathrm{Ba}, \mathrm{Os}, \mathrm{Ch}$ \\
\hline PCL & 1000 & 90 & - & - & $\mathrm{Ba}, \mathrm{Os}, \mathrm{Ch}$ \\
\hline$P(L \backslash D L) L A$ & 1000 & 90 & - & - & $\mathrm{Ba}, \mathrm{Os}, \mathrm{Ch}$ \\
\hline \multicolumn{6}{|c|}{ Tribology material } \\
\hline PEOT/PBT & 1000 & 90 & 0.15 & 2.0 & - \\
\hline PEOT/PBT & 1000 & 90 & 1.00 & 2.0 & - \\
\hline $\mathrm{PCL}$ & 1000 & 90 & 0.15 & 2.0 & - \\
\hline PCL & 1000 & 90 & 1.00 & 2.0 & - \\
\hline$P(L \backslash D L) L A$ & 1000 & 90 & 0.15 & 2.0 & - \\
\hline$P(L \mid D L) L A$ & 1000 & 90 & 1.00 & 2.0 & - \\
\hline \multicolumn{6}{|c|}{ Tribology architectures } \\
\hline РEOT/PBT & 1000 & 90 & 0.15 & 2.0 & - \\
\hline РEOT/PBT & 1000 & 90 & 1.00 & 2.0 & - \\
\hline PEOT/PBT & 800 & 90 & 0.15 & 2.0 & - \\
\hline PEOT/PBT & 800 & 90 & 1.00 & 2.0 & - \\
\hline РEOT/PBT & 800 & 90 & 1.00 & 0.2 & - \\
\hline РEOT/PBT & 600 & 90 & 0.15 & 2.0 & - \\
\hline PEOT/PBT & 600 & 90 & 1.00 & 2.0 & - \\
\hline РEOT/PBT & 600 & 90 & 1.00 & 0.2 & - \\
\hline PEOT/PBT & 600 & 45 & 0.15 & 2.0 & - \\
\hline \multicolumn{6}{|c|}{ Biological and tribological } \\
\hline РEOT/PBT & 1000 & 90 & 0.15 & 2.0 & $\mathrm{Ba}, \mathrm{Ch}$ \\
\hline PEOT/PBT & 1000 & 90 & 1.00 & 2.0 & $\mathrm{Ba}, \mathrm{Ch}$ \\
\hline PEOT/PBT & 1000 & 90 & 1.00 & 0.2 & $\mathrm{Ba}, \mathrm{Ch}$ \\
\hline РEOT/PBT & 600 & 90 & 0.15 & 2.0 & $\mathrm{Ba}, \mathrm{Ch}$ \\
\hline РEOT/PBT & 600 & 90 & 1.00 & 2.0 & $\mathrm{Ba}, \mathrm{Ch}$ \\
\hline РEOT/PBT & 600 & 90 & 1.00 & 0.2 & $\mathrm{Ba}, \mathrm{Ch}$ \\
\hline
\end{tabular}

Scanning Electron Microscopy: Formalin-fixated scaffolds samples were dehydrated through an ethanol series. $\mathrm{P}(\mathrm{L} \backslash \mathrm{DL}) \mathrm{LA}$ and PEOT/PBT samples were transferred to a critical point dryer (CPD 030 BAL-TEC), while the PCL samples were immersed in hexamethyldisilazane (HMDS, Sigma) for 15 min after total dehydration. Excessive HMDS was removed and the PCL samples were left to dry overnight. The dried samples were mounted on a stage, gold sputtered, and imaged with an SEM (XL-30 ESEM-FEG, Phillips).

Friction Measurements: The tribological tests were conducted with a ball-on-plate rig by using a Nano Tribometer from CSM-instruments (Figure S1, Supporting Information). The stationary part was the scaffold specimen measuring $8 \mathrm{~mm}$ in diameter and $2.1 \mathrm{~mm}$ in thickness. The rotating part was a PU spherical cap. The PU granular material, PEARLTHANE DIIT92EM, was provided by Merquinsa (Montmelo, Spain). The modulus at $100 \%$ elongation (test method ISO527) was $8 \mathrm{MPa}$ according to the supplier's information, which is within the range of the equilibrium tensile modulus of human articular cartilage (1-30 MPa). ${ }^{[46]}$ The $10 \mathrm{~mm}$ diameter spherical cap was made from the PU granules by injection moulding. All the experiments were conducted at room temperature with relative humidity between $20 \%$ and $40 \%$. The lubricant used was PBS from Lonza. Normal loads were set to 0.15 or $1.00 \mathrm{~N}$, with a rotating velocity of either 0.2 or $2.0 \mathrm{~mm} \mathrm{~s}^{-1}$ (Table 1). Normal loads were selected based on the instrument limitation and targeting contact pressure of articular synovial joint $(0.1-20 \mathrm{MPa}) \cdot{ }^{[47]}$ Assuming initially a contact configuration of a $10 \mathrm{~mm}$ diameter PU spherical cap versus a flat PEOT/PBT film, the contact pressure calculated by using the Hertz model was $\approx 0.5$ and $1.0 \mathrm{MPa}$ at 0.15 and $1.00 \mathrm{~N}$, respectively. When the flat PEOT/PBT film was changed to a PEOT/PBT scaffold as used in this study, the contact pressure was expected to be higher than this calculated value due to the reduction of real contact area. Each test run was conducted for 120 rotations $(\approx 1.5 \mathrm{~m}$ in distance) and repeated three times. The equilibrium value was reported.

Interference Microscopy: The surface topography and roughness of the PU cap before and after each tribological test were measured by using a Micromap 560 Interference Microscope. The average surface roughness of the spherical cap (Sa) before each test was $150 \pm 20 \mathrm{~nm}$.

Statistical Analysis: A Two way ANOVA with Bonferroni's post hoc test was used to analyze the biological test results. A One way ANOVA with Tukey's post hoc test was used to analyze the tribological test results. $P$ values less than 0.05 were considered to be statistically significant. All values are reported as average mean with standard deviation.

\section{Supporting Information}

Supporting Information is available from the Wiley Online Library or from the author. 


\section{Acknowledgements}

W.J.H. and X.Z. contributed equally to this work. The authors gratefully acknowledge funding from European FP7 Marie Curie Career Integration Grant (PCIG10-GA-2011-303922) to X.Z. The authors would also like to acknowledge funding for W.H. from the Netherlands Institute of Regenerative Medicine (contract grant number: FES0908). The research of J.R. was financially supported by a VENI grant by the Dutch Technology Foundation STW.

Received: January 28, 2015

Revised: September 8, 2015

Published online: November 25, 2015

[1] M. J. M. D. Angel, P. M. S. Razzano, D. A. P. Grande, Sports Med. Arthroscopy Rev. 2003, 11, 168.

[2] S. W. O'Driscoll, J. Bone Jt. Surg. Am. 1998, 80, 1795.

[3] Y. Mei, K. Saha, S. R. Bogatyrev, J. Yang, A. L. Hook, Z. I. Kalcioglu, S. W. Cho, M. Mitalipova, N. Pyzocha, F. Rojas, K. J. Van Vliet, M. C. Davies, M. R. Alexander, R. Langer, R. Jaenisch, D. G. Anderson, Nat. Mater. 2010, 9, 768.

[4] H. V. Unadkat, M. Hulsman, K. Cornelissen, B. J. Papenburg, R. K. Truckenmüller, G. F. Post, M. Uetz, M. J. T. Reinders, D. Stamatialis, C. A. van Blitterswijk, J. de Boer, Proc. Natl. Acad. Sci. USA 2011, 108, 16565.

[5] N. Huebsch, P. R. Arany, A. S. Mao, D. Shvartsman, O. A. Ali, S. A. Bencherif, J. Rivera-Feliciano, D. J. Mooney, Nat. Mater. 2010, 9, 518.

[6] H. Yuan, H. Fernandes, P. Habibovic, J. de Boer, A. M. C. Barradas, A. de Ruiter, W. R. Walsh, C. A. van Blitterswijk, J. D. de Bruijn, Proc. Natl. Acad. Sci. USA 2010, 107, 13614.

[7] M. T. Arafat, C. X. F. Lam, A. K. Ekaputra, S. Y. Wong, X. Li, I. Gibson, Acta Biomaterialia 2011, 7, 809.

[8] J. Zhang, X. Luo, D. Barbieri, A. M. C. Barradas, J. D. de Bruijn, C. A. van Blitterswijk, H. Yuan, Acta Biomaterialia 2014, 10, 3254.

[9] M. A. Woodruff, D. W. Hutmacher, Prog. Polym. Sci. 2010, 35, 1217.

[10] S.-h. Hsu, H.-J. Yen, C.-S. Tseng, C.-S. Cheng, C.-L. Tsai, J. Biomed. Mater. Res. Part B: Appl. Biomater. 2007, 80B, 519.

[11] L. Shor, S. Güçeri, R. Chang, J. Gordon, Q. Kang, L. Hartsock, Y. An, W. Sun, Biofabrication 2009, 1, 015003.

[12] L. Shor, S. Güçeri, X. Wen, M. Gandhi, W. Sun, Biomaterials 2007, 28, 5291.

[13] I. Zein, D. W. Hutmacher, K. C. Tan, S. H. Teoh, Biomaterials 2002, 23, 1169.

[14] A. M. Leferink, W. J. Hendrikson, J. Rouwkema, M. Karperien, C. A. van Blitterswijk, L. Moroni, J. Tissue Eng. Regen. Med. 2013.

[15] T. B. F. Woodfield, J. Malda, J. de Wijn, F. Péters, J. Riesle, C. A. van Blitterswijk, Biomaterials 2004, 25, 4149.

[16] J. Malda, T. B. F. Woodfield, F. van der Vloodt, C. Wilson, D. E. Martens, J. Tramper, C. A. van Blitterswijk, J. Riesle, Biomaterials 2005, 26, 63 .

[17] S. K. Bulstra, R. G. Geesink, D. Bakker, T. H. Bulstra, S. J. Bouwmeester, A. J. van der Linden, J. Bone Jt. Surg. Br. 1996, 78, 892.

[18] C. Du, G. J. Meijer, C. van de Valk, R. E. Haan, J. M. Bezemer, S. C. Hesseling, F. Z. Cui, K. de Groot, P. Layrolle, Biomaterials 2002, 23, 4649 .
[19] G. J. Meijer, A. van Dooren, M. L. Gaillard, R. Dalmeijer C. de Putter, R. Koole, C. A. van Blitterwijk, Int. J. Oral. Maxillofac. Surg. 1996, 25, 210.

[20] P. J. Emans, E. J. P. Jansen, D. van lersel, T. J. M. Welting, T. B. F. Woodfield, S. K. Bulstra, J. Riesle, L. W. van Rhijn, R. Kuijer, J. Tissue Eng. Regen. Med. 2013, 7, 751.

[21] W. J. Hendrikson, C. A. van Blitterswijk, N. Verdonschot, L. Moroni, J. Rouwkema, Biotechnol. Bioeng. 2014, 111, 1864.

[22] J. A. A. Hendriks, L. Moroni, J. Riesle, J. R. de Wijn, C. A. van Blitterswijk, Biomaterials 2013, 34, 4259.

[23] J. Korpela, A. Kokkari, H. Korhonen, M. Malin, T. Närhi, J. Seppälä, J. Biomed. Mater. Res. Part B: Appl. Biomater. 2013, 101B, 610.

[24] C. G. Jeong, S. J. Hollister, Biomaterials 2010, 31, 4304.

[25] M. A. Accardi, S. D. McCullen, A. Callanan, S. Chung, P. M. Cann, M. M. Stevens, D. Dini, Tissue Eng. Part A 2013, 19, 2300.

[26] F. T. Moutos, B. T. Estes, F. Guilak, Macromol. Biosci. 2010, 10 1355.

[27] F. T. Moutos, F. Guilak, Tissue Eng. Part A 2010, 16, 1291.

[28] I. C. Liao, F. T. Moutos, B. T. Estes, X. Zhao, F. Guilak, Adv. Funct. Mater. 2013, 23, 5833.

[29] M. B. Mueller, M. Fischer, J. Zellner, A. Berner, T. Dienstknecht, L. Prantl, R. Kujat, M. Nerlich, R. S. Tuan, P. Angele, Cells Tissues Organs 2010, 192, 158.

[30] C. K. Abrahamsson, F. Yang, H. Park, J. M. Brunger, P. K. Valonen, R. Langer, J. F. Welter, A. I. Caplan, F. Guilak, L. E. Freed, Tissue Eng. Part A 2010, 16, 3709.

[31] J. K. Wise, A. L. Yarin, C. M. Megaridis, M. Cho, Tissue Eng. Part A 2009, 15, 913

[32] R. Tuli, S. Nandi, W. J. Li, S. Tuli, X. X. Huang, P. A. Manner, P. Laquerriere, U. Noth, D. J. Hall, R. S. Tuan, Tissue Eng. 2004, 10, 1169.

[33] B. Bhushan, Introduction to Tribology, Wiley, New York, 2002.

[34] L. Moroni, J. R. de Wijn, C. A. van Blitterswijk, J. Biomed. Mater. Res. A 2005, 75, 957.

[35] L. Moroni, J. R. de Wijn, C. A. van Blitterswijk, Biomaterials 2006, 27 , 974.

[36] L. Moroni, G. Poort, F. Van Keulen, J. R. de Wijn, C. A. van Blitterswijk, J. Biomed. Mater. Res. A 2006, 78, 605.

[37] N. K. Myshkin, M. I. Petrokovets, A. V. Kovalev, Tribol. Int. 2005, 38, 910.

[38] L. Shi, V. I. Sikavitsas, A. Striolo, Ann. Biomed. Eng. 2011, 39, 132.

[39] J. P. Gleghorn, L. J. Bonassar, J. Biomech. 2008, 41, 1910.

[40] G. A. Ateshian, J. Biomech. 2009, 42, 1163.

[41] E. D. Bonnevie, V. J. Baro, L. Wang, D. L. Burris, Tribol. Lett. 2011, 41,83 .

[42] M. Caligaris, G. A. Ateshian, Osteoarthritis Cartilage 2008, 16, 1220.

[43] C. P. Neu, K. Komvopoulos, A. H. Reddi, Tissue Eng. Part B: Rev. 2008, 14, 235.

[44] Y. Merkher, S. Sivan, I. Etsion, A. Maroudas, G. Halperin, A. Yosef, Tribol. Lett. 2006, 22, 29.

[45] J. D. de Bruijn, I. van den Brink, S. Mendes, R. Dekker, Y. P. Bovell, C. A. van Blitterswijk, Adv. Dent. Res. 1999, 13, 74.

[46] S. Akizuki, V. C. Mow, F. Muller, J. C. Pita, D. S. Howell, D. H. Manicourt, J. Orthop. Res. 1986, 4, 379.

[47] Chondrocytes, Mechanical Forces: Their Effects on Cells and Tissues (Eds: K. Gooch, C. Tennant), Springer, Heidelberg 1997, pp. 79-100. 